ORIGINAL ARTICLE

\title{
The effects of occupational exposure to chlorpyrifos on the peripheral nervous system: a prospective cohort study
}

\author{
J W Albers, D H Garabrant, S J Schweitzer, R P Garrison, R J Richardson, S Berent
}

Occup Environ Med 2004;61:201-211. doi: 10.1136/oem.2003.008847

\begin{abstract}
See end of article for authors' affiliations

Correspondence to: Dr J W Albers, Department of Neurology, 1C325/ 0032 University Hospital, University of Michigan Health System, 1500 E. Medical Center Drive, Ann Arbor, Ml 48109-0032, USA; jwalbers@umich.edu

Accepted 25 September 2003
\end{abstract}

\begin{abstract}
Aims: To determine whether chronic occupational exposure to chlorpyrifos at levels associated with various aspects of manufacturing produced a clinically evident or subclinical peripheral neuropathy. Methods: Clinical and quantitative nerve conduction study (NCS) examinations were performed on two occasions on chlorpyrifos manufacturing workers who had measurable chlorpyrifos exposure and a referent group. Baseline evaluations were performed on 53 of 66 eligible chlorpyrifos subjects and on 60 of 74 eligible referent subjects; one-year evaluations were completed on 111 of the 113 subjects evaluated at baseline.

Results: Chlorpyrifos and referent groups differed significantly in measures of 3,5,6 trichloro-2-pyridinol excretion and plasma butyrylcholinesterase (BuChE) activity, indicating substantially higher exposures among chlorpyrifos subjects. Few subjects had clinically important neurological symptoms or signs. NCS results were comparable to control values, and there were no significant group differences in NCS results at baseline, one year, or change over one year. No chlorpyrifos subject fulfilled conventional criteria for confirmed peripheral neuropathy at baseline or one-year examinations. The odds ratios for developing any diagnosable level of peripheral neuropathy among the chlorpyrifos subjects was not increased at baseline or at one year compared to referents at baseline. Mixed regression models used to evaluate subclinical group-by-time interactions showed numerous significant NCS differences attributable to nearnerve temperature differences among all subjects between the baseline and one-year examinations, but only a few disparate effects related to group.

Conclusions: Chronic chlorpyrifos exposure during the manufacturing process sufficient to produce biological effects on BuChE activity was not associated with clinically evident or subclinical peripheral neuropathy at baseline or with measurable deterioration among chlorpyrifos subjects compared to referents after one year of additional exposure.
\end{abstract}

$\mathrm{C}$ hlorpyrifos is a widely used and studied organophosphorus (OP) insecticide. Despite this, the perception of the risk of injury, especially as a result of low level exposures to pesticides, has been said to vary widely. ${ }^{1}$ The intended mode of action of chlorpyrifos and other OP insecticides involves acute cholinergic toxicity due to inhibition of acetylcholinesterase (AChE) in nerve endings. ${ }^{2} \mathrm{~A}$ consequence of poisoning with some OP compounds is to produce OP induced delayed neurotoxicity (OPIDN) through inhibition and aging of neuropathy target esterase in neural tissues, ${ }^{34}$ and it remains uncertain if prolonged or repeated exposures to low doses of chlorpyrifos which do not produce overt cholinergic signs produce neurological dysfunction independent of OPIDN. Despite the substantial amount of information about the safety of chlorpyrifos with respect to delayed toxicity, ${ }^{3}{ }^{5}$ some studies suggest that chlorpyrifos may adversely affect behaviour in rats as a result of prenatal exposure, ${ }^{6}$ although exposures routes were by subcutaneous injection with a DMSO vehicle and therefore not germane to human exposure and effects showed no dose-response and were restricted to one sex. It remains uncertain whether prolonged or repeated exposures to low doses of chlorpyrifos which do not produce overt cholinergic signs produce neurological dysfunction in humans independent of OPIDN. Nevertheless, peripheral nervous system effects attributed to chlorpyrifos exposure which are unrelated to the known cholinergic effects associated with acute poisoning are considered by most scientists to be unproven. The primary reason for this position is that the information attributing these adverse neurological effects to chlorpyrifos or other OP insecticides in humans is based on individual case reports, case reports of a small number of exposed individuals, ${ }^{7}$ crosssectional studies, ${ }^{8-10}$ or the results reported could not be replicated using similar methodologies. ${ }^{11}$

Overall, there is no consistent evidence that environmental or occupational exposure to chlorpyrifos causes adverse neurological outcomes unrelated to the known cholinergic effects associated with acute poisoning. ${ }^{12}{ }^{13}$ A recent assessment of the literature involving the association between low level exposure to OP esters and peripheral nerve function concluded that peripheral nervous system abnormalities among subjects with current or past exposures to OP esters were mild, inconsistent, and unexplained. ${ }^{14}$ These dissimilar results and lack of harmonious findings across studies suggest that factors other than OP exposure account for the collective findings. It is possible that adverse effects result from mechanisms other than AChE inhibition, as low level exposures insufficient to produce cholinergic signs produce a variety of effects, positive and negative, in experimental animals. ${ }^{13}$ At present, there is inadequate information from epidemiological studies to determine whether adverse neurological effects result from low level exposure, such as occurs in the manufacture of chlorpyrifos.

Abbreviations: $\mathrm{AChE}$, acetylcholinesterase; BuChE, butyrylcholinesterase; $\mathrm{C}$, Celsius; $\mathrm{g}-\mathrm{Cr}$, gram-creatinine; NCS, nerve conduction study; OP, organophosphorus; PEL, permissible exposure level; TCP, 3,5,6 trichloro-2-pyridinol 


\section{Main messages}

- Measurable exposure to chlorpyrifos occurs during various aspects of the manufacturing process in a range where physiological effects on B-esterases, including BuChE, exist.

- No support was found for the hypothesis that workers with chronic occupational exposure to chlorpyrifos during the manufacturing process develop clinically evident or subclinical peripheral neuropathy, and there was no evidence of clinically evident or subclinical deterioration among the chlorpyrifos subjects over one year of chlorpyrifos exposure compared to the referent group.

- Among subjects with measurable chlorpyrifos exposure in the chlorpyrifos group, no subject fulfilled conventional criteria for confirmed peripheral neuropathy at baseline or one-year examinations.

Dow AgroSciences, with the support of the Environmental Protection Agency (EPA), convened an expert panel in July 1997 to address these concerns. ${ }^{15}$ This panel critically reviewed available published and unpublished information related to potential adverse neurological health effects associated with chlorpyrifos. ${ }^{16}$ Based on assessment of the scientific literature at the time, a majority of panel members felt there was insufficient evidence of adverse neurological health effects to necessitate additional studies of the effects of long term or low level exposure. A minority of panel members, however, felt that such studies were justified. The expert panel reached consensus that the potential neurological and neurobehavioural effects of chlorpyrifos should be evaluated using a population of workers with occupational chlorpyrifos exposure. ${ }^{16}$ In response to the panel's report of consensus recommendations, Dow AgroSciences prepared a request for proposal (RFP) to address the potential human neurobehavioural and neurological effects of chlorpyrifos. The proposal submitted by the University of Michigan investigators was selected from among a number of responses to this RFP by an independent panel of reviewers. The resultant study was designed to determine whether workers with chronic occupational exposure to chlorpyrifos develop adverse neurobehavioural or neurological effects, including peripheral neuropathy. The evaluation of peripheral neuropathy is addressed in the material that follows. Chlorpyrifos manufacturers were targeted for study because they are believed to have greater opportunity for chlorpyrifos exposure than the general population, and because they have measurable exposure to chlorpyrifos, but no occupational exposure to other OP insecticides or other potential neurotoxicants.

A Committee on Toxicity of Chemicals in Food, Consumer Products, and the Environment convened by the United Kingdom Department of Health (1999) also reviewed the evidence that associates neuropathy with chronic, low level exposures to OP insecticides. ${ }^{17}$ The committee concluded that the balance of evidence suggested that repeated acute or chronic exposures to OPs at doses lower than those causing frank toxicity either do not cause neuropathy or do so only rarely. Like the Dow AgroSciences panel, they recommended further investigation to establish whether the risk of neurological disease is increased by low level OP exposures, exposure levels comparable to those evaluated in our study.

\section{Policy implications}

- Chronic occupational exposure to chlorpyrifos during the manufacturing process at levels averaging approximately $30 \%$ (range $0-250 \%$ ) of that received by a typical subject exposed during a working day at the permissible exposure level (PEL) of $200 \mu \mathrm{g} / \mathrm{m}^{3}$ is not associated with development of a subclinical or clinically evident peripheral neuropathy.

\section{METHODS}

\section{Study design}

We evaluated two groups of chemical workers at the Dow Chemical Company in Midland, Michigan. We evaluated peripheral nervous system function on two occasions and related these evaluations to measures of chlorpyrifos exposure. This prospective cohort study assessed two groups of subjects at baseline and after an interval of one year. The first group consisted of chlorpyrifos manufacturing workers who had known and measurable exposure to chlorpyrifos, but no occupational exposure to other OP insecticides or to other neurotoxicants. The second group consisted of chemical workers involved in manufacturing Saran (clear plastic film wrapping material) who had no occupational exposure to chlorpyrifos or other known or suspected neurotoxicants. This referent group was chosen to control for potential factors associated with employment in the chemical industry. For chlorpyrifos subjects, the baseline examination occurred during a period of potential chlorpyrifos exposure, and the second examination occurred after approximately one year of additional exposure. The referent subjects were studied concurrently with the chlorpyrifos subjects. Subjects were scheduled so that the investigators examined both chlorpyrifos and referent subjects on any given day without indication of the individual subject's group membership. All clinical examiners and those performing biomarker analyses were masked to individual exposure histories.

\section{Subject selection}

Dow Chemical Company employees were eligible for participation if they satisfied the following: age between 18 and 65 , male or female; no physician diagnosed condition that would make them unable to participate in the tests or complete the protocol; and ability to read, understand, and sign informed consent forms. No subject was eliminated because of a physician diagnosed condition. There were additional eligibility criteria not directly relevant to the evaluation of the peripheral nervous system examination, such as the ability to read English at a fifth grade level or higher, and no involvement in disability applications or litigation against Dow Chemical Company. No subject was excluded based on these additional eligibility criteria. All eligible chlorpyrifos manufacturing workers, defined as those employed on l September 1999 in any of buildings involved in the chlorpyrifos production, were asked to participate. A random sample of Saran manufacturing workers, defined as those employed on l September 1999 in the Saran production building, was chosen and asked to participate as a referent population. The study was explained to eligible participants and subjects were given opportunities to ask questions regarding the protocol and conduct of the study. All participants read and signed an informed consent form indicating their willingness to participate. The study was approved by the University of Michigan Institutional Review Board for Human Subject Research 
and the Dow Chemical Company Human Subject Review Board.

\section{Exposure assessment}

Estimates of ambient chlorpyrifos exposure were derived from industrial hygiene measurements. Industrial hygiene records were reviewed to establish estimates of interim cumulative chlorpyrifos exposure during the year between the baseline and one year follow up examinations and historic cumulative chlorpyrifos exposure from the time of initial employment to the baseline examination. The chlorpyrifos exposure assessment included estimates of airborne levels based on historical personal air sampling data. These historical data were compiled for similarly exposed groups (SEGs) of workers, and geometric mean exposure levels were calculated for each SEG. These mean data were used to establish the estimates of historic chlorpyrifos exposure. Interim cumulative and historic cumulative chlorpyrifos exposures were calculated by multiplying the exposure estimate for each SEG by the number of days worked in the job and summing these products across jobs. For historic cumulative chlorpyrifos exposure, all jobs in the subject's career up to the date of the first examination were used. For interim cumulative chlorpyrifos exposure, all jobs from the date of the first examination to the date of the one-year examination were used. Chlorpyrifos exposure also was assessed biologically during the year between the baseline and one year follow up examinations by urinary excretion of 3,5,6 trichloro-2-pyridinol (TCP), a metabolite of chlorpyrifos, plasma butyrylcholinesterase (BuChE) activity, and red blood cell acetylcholinesterase (AChE) activity. The urine TCP was reported as a weighted average of four overnight collections ( $\mu \mathrm{g}$ TCP) divided by creatinine $(\mathrm{Cr})$ concentration in grams (TCP/Cr). Monthly plasma BuChE activities $(\mathrm{mU} / \mathrm{ml})$ were assessed and averaged during the same interval. RBC AChE activities were obtained at baseline and one-year examinations.

\section{Questionnaires}

Participants were interviewed in person by a trained interviewer using a standardised questionnaire which included questions about demographics, chemical exposures at home and at work, family history of neurological diseases, personal medical history including medications, and social history including alcohol use and possible non-occupational exposures to insecticides. The alcohol history included a self report of the types (beer, wine, liquor), frequency (per week or per month), and amount (bottles, 4 ounce glasses, 1.5 ounce shots) of alcohol use during different time intervals (age 15-17, 18-22, 23-30, and per decade thereafter), and identification of known or suspected alcohol abuse, participation in treatment programmes, and history of traffic violations related to intoxication.

\section{Medical and neurological evaluations}

General medical examinations were performed by an internist and occupational medicine specialist to detect medical conditions that potentially produce nervous system abnormalities. The examination included measurement of vital signs, ophthalmoscopy, palpation of the thyroid, auscultation of the heart and lungs, palpation of the abdomen, assessment of peripheral pulses, carotid auscultation, and assessment of the lymph nodes.

Neurological evaluations were performed by a neurologist to elicit sensory symptoms (loss of feeling, paraesthesias, numbness or tingling, pins and needles sensation, imbalance), and motor symptoms (weakness), and to identify neurological abnormalities (signs). The peripheral nervous system examination included evaluation of strength (proximal and distal); station (Romberg); gait; muscle stretch reflexes (wrist, knee, and ankle); and sensation (fine touch, von Frey monofilament, joint position sensation, pinpain, and vibration). Sensation was tested at the dominant index finger and great toe, and, if abnormal, contralaterally. Examination results consisted of ordinal graded responses for all components.

\section{Nerve conduction studies}

Conventional nerve conduction studies (NCSs) were performed on the dominant side sensory and motor nerves. Antidromic median, ulnar, and sural sensory baseline to negative peak amplitude, onset latency, and negative peak latency were recorded from digit II, digit V, and the ankle, respectively, using $14 \mathrm{~cm}$ stimulation to recording electrode distances. Median and peroneal motor conduction studies used a 7 and $9 \mathrm{~cm}$ stimulation to recording electrode distance to the abductor pollicis brevis and extensor digitorum brevis muscles, respectively. Motor response amplitude (baseline to negative peak), onset latency, and F wave latency (antidromic stimulation at the wrist and ankle) were recorded. The median motor conduction velocity (forearm segment) was calculated. At baseline, limb temperatures (palm and leg) were monitored and limbs were warmed when necessary using an electrical heating pad to maintain temperatures above $32{ }^{\circ} \mathrm{C}$ (palm) and $31^{\circ} \mathrm{C}$ (foot). At the one-year examination, the baseline temperatures were available to the electromyographer for each subject, and the examiner attempted to reproduce the limb temperatures within $0.5^{\circ} \mathrm{C}$. Nerve conduction abnormalities were based on published values using comparable techniques. ${ }^{18-20}$ The values used to define abnormalities were comparable to those used clinically at the University of Michigan Electromyography Laboratory, as defined for normal, healthy adults (approximately 95th centile values).

Summary amplitude and conduction velocity $\mathrm{Z}$ scores were calculated for motor (median and peroneal) and sensory (median, ulnar, and sural) nerves using NCS results obtained from Saran subjects. Data were inspected to determine whether they needed transformation prior to analyses to make them more normally distributed. Amplitude Z scores were calculated using distal amplitude measures. Conduction velocity $\mathrm{Z}$ scores were calculated using distal latency, terminal conduction velocity (for sensory nerves), and extremity conduction velocity information after transforming latency measures (negative values) so that a higher value always indicated faster conduction.

\section{Neuropathy outcome variables}

Subclinical or clinically evident neuropathy was defined using a combination of symptoms, signs, and NCS results as consistent with standard clinical practice. ${ }^{21} 22$ Probable neuropathy was defined as the presence of abnormalities consistent with a sensory or sensorimotor neuropathy in at least two of the following three categories: symptoms, peripheral sensation, or decreased ankle reflexes (trace or absent). Symptoms accepted as consistent with neuropathy included report of persistent and symmetric stocking or stocking-glove distribution numbness, tingling, or sensory loss. Because no subject reported persistent sensory symptoms consistent with neuropathy at the baseline or one-year examinations, the definition was extended to include subjects with intermittent symmetric stocking or stocking-glove distribution sensory symptoms. Sensory signs accepted as consistent with neuropathy included evidence of symmetric stocking or stocking-glove distribution sensory loss among tests of touch, von Frey monofilament, joint position, pin-pain, or vibration sensation. Subjects with a single appropriate abnormality among symptoms, sensation, or reflexes were labelled possible 
neuropathy. Confirmed neuropathy required a diagnosis of possible neuropathy or probable neuropathy and abnormal electrodiagnostic testing consisting of at least one abnormal NCS measure in two peripheral nerves. ${ }^{23}$ Subjects without symptoms or signs of neuropathy who had at least one abnormal NCS measure in two peripheral nerves were labelled subclinical neuropathy.

\section{Statistical analyses}

All questionnaire, medical examination, and electrodiagnostic results were computerised, and data were double entered or hand checked against the original records for accuracy. Data were managed in Microsoft Access and Excel. Data analyses were performed in SAS, version 8.2 (SAS Institute, Cary, NC). Analyses included comparison of clinical, laboratory, and electrophysiological results relevant to the evaluation of peripheral neuropathy for the chlorpyrifos group and the referent group at baseline, one-year examination, and change over one year ( $t$ test for difference in means and Fisher exact test or $\chi^{2}$ test for frequency count data). Logistic regression analysis was used to calculate the odds ratio for developing clinical signs of neuropathy or any diagnosable level of peripheral neuropathy among chlorpyrifos subjects at either of the two examinations compared to the referent group at baseline. Mixed regression models were utilised to account for repeated measures on individuals over time. Models included the main effects of group (chlorpyrifos or referent) and time (baseline or one-year) as well as an interaction term. These models were used to evaluate the interaction between group and time to determine whether chlorpyrifos exposure was associated with changes in NCS results over time. Potential confounders of primary interest included age, sex, height, weight, body mass index (BMI), and skin temperature over the nerve being tested. In addition, we evaluated smoking (pack-years), socioeconomic status (estimated general ability (NART-R) ${ }^{24}$ and education level), and anxiety ${ }^{25}$ because they were believed a priori to be potential confounders. ${ }^{26-28}$ A stepwise selection procedure was used to include covariates that had a $\mathrm{p}$ value $<0.15$. In order to determine whether any of these covariates was a confounder, we compared the parameter estimate for the group-by-time interaction term in a simple model using group, time, and group-by-time to the parameter estimate in an adjusted model with group, time, group-by-time, and all of the potential confounders. If the parameter estimate for the group-by-time effect in the adjusted model differed by less than one standard error from the parameter estimate for the simple model, we determined that no appreciable amount of confounding was present and the simple model was more appropriate. In order to make a conservative judgment, the smallest standard error from the simple and adjusted models was chosen for these calculations.

\section{RESULTS}

\section{Subjects}

Fifty three of the 66 eligible chlorpyrifos workers (80\%) participated. Seventy four Saran workers were chosen at random and asked to participate. Of these, 60 (81\%) participated. Examinations were performed approximately one year after the baseline examinations on 111 of the initial 113 subjects (98\%). Two subjects from the referent group elected not to participate in the one-year examinations.

\section{Baseline characteristics}

Table 1 shows characteristics of the study sample. Referents were comparable to the chlorpyrifos subjects in terms of age, sex, anthropometric features, smoking history, and anxiety level. Overall, participants were early middle age, mostly male, and white $(90 \%)$. They were of average height but
Table 1 Comparison of gender, age, anthropometric, and other data for chlorpyrifos (CPF; $n=53$ ) and referent $(n=60)$ subjects at baseline

\begin{tabular}{|c|c|c|c|}
\hline Variable & $\begin{array}{l}\text { CPF } \\
\%\end{array}$ & $\begin{array}{l}\text { Referent } \\
\%\end{array}$ & p value* \\
\hline Gender & & & 0.62 \\
\hline Female & 22.6 & 26.7 & \\
\hline Male & 77.4 & 73.3 & \\
\hline \multirow[t]{2}{*}{ Body mass index $>29.0$} & 50.9 & 43.3 & 0.45 \\
\hline & Mean (SD) & Mean (SD) & $p$ valuet \\
\hline Age (years) & $41.2(7.5)$ & $41.3(8.4)$ & 0.92 \\
\hline Height (m) & $1.74(0.1)$ & $1.75(0.1)$ & 0.94 \\
\hline Weight $(\mathrm{kg})$ & $88.1(15.0)$ & $88.3(20.3)$ & 0.96 \\
\hline Body mass index $\left(\mathrm{kg} / \mathrm{m}^{2}\right)$ & $29.0(4.2)$ & $29.0(6.0)$ & 0.99 \\
\hline Education level & $14.3(2.1)$ & $13.6(1.5)$ & 0.06 \\
\hline Estimated general ability $\ddagger$ & $106.2(9.2)$ & $104.0(9.1)$ & 0.21 \\
\hline Smoking (pack-years) & $8.2(15.8)$ & $5.9(9.5)$ & 0.37 \\
\hline Anxiety§ & $48.0(11.8)$ & $47.8(13.8)$ & 0.93 \\
\hline
\end{tabular}

*Fisher's exact test or $\chi^{2}$ test.

t $t$ test for difference in means.

‡Revision of the North American Reading Test (NART-R). ${ }^{24}$

§Brief Symptom Inventory (BSI). ${ }^{25}$

above average weight, and $47 \%$ had a body mass index (BMI) exceeding 29.0, the level considered obese. The overall frequency of most medical problems did not differ significantly between the chlorpyrifos and referent groups. This included a similar distribution of subjects with disorders that could contribute to neurological or NCS abnormalities, including diabetes mellitus ( 1 chlorpyrifos, 1 referent; $p>0.99)$. Reported hand injury or hand fracture was significantly higher among the referent subjects than among chlorpyrifos subjects ( $33 v 11 ; \mathrm{p}=0.0002)$. Alcohol use was similar for both groups. Fourteen subjects $(6$ chlorpyrifos, 8 referent; $\mathrm{p}>0.99$ ) had been told at some time that they had an alcohol problem, and 13 subjects ( 3 chlorpyrifos and 10 referent; $\mathrm{p}=0.08$ ) reported an arrest for driving under the influence (DUI) of alcohol. At baseline, one patient in each group was taking a prescription medication potentially associated with neuropathy. One additional subject in the chlorpyrifos group had previously taken (years before) a chemotherapeutic medication with neurotoxic potential. At the one-year examination, one of the two subjects (a referent) previously taking a prescribed medication potentially associated with neuropathy continued to do so. The interval questionnaire identified no subjects who had been diagnosed since the baseline examination with a new systemic illness that could potentially contribute to signs of neuropathy or NCS abnormalities.

\section{Exposure assessment}

Table 2 shows descriptive statistics for the exposure variables and biological monitoring results for chlorpyrifos subjects and referents. The industrial hygiene measures showed substantial differences between the chlorpyrifos subjects and the referent subjects for historic cumulative chlorpyrifos exposure $\left(64.16 v 0.69 \mathrm{mg} / \mathrm{m}^{3 *}\right.$ days; $\left.\mathrm{p}<0.0001\right)$, duration of work in exposed areas $(9.72 v 0.01$ years; $p<0.0001)$, and interim chlorpyrifos exposure $\left(6.13 \vee 0.00 \mathrm{mg} / \mathrm{m}^{3 *}\right.$ days; $\mathrm{p}<0.0001)$. During the period of observation, none of the referents had any identifiable exposure to chlorpyrifos in their jobs. Although some referent subjects had occasionally worked in chlorpyrifos exposed jobs in past years, the referent group historical cumulative exposure was dramatically lower (approximately 100-fold) than among the chlorpyrifos workers. Among chlorpyrifos subjects, the interim chlorpyrifos exposures were comparable to yearly exposures experienced previously. 


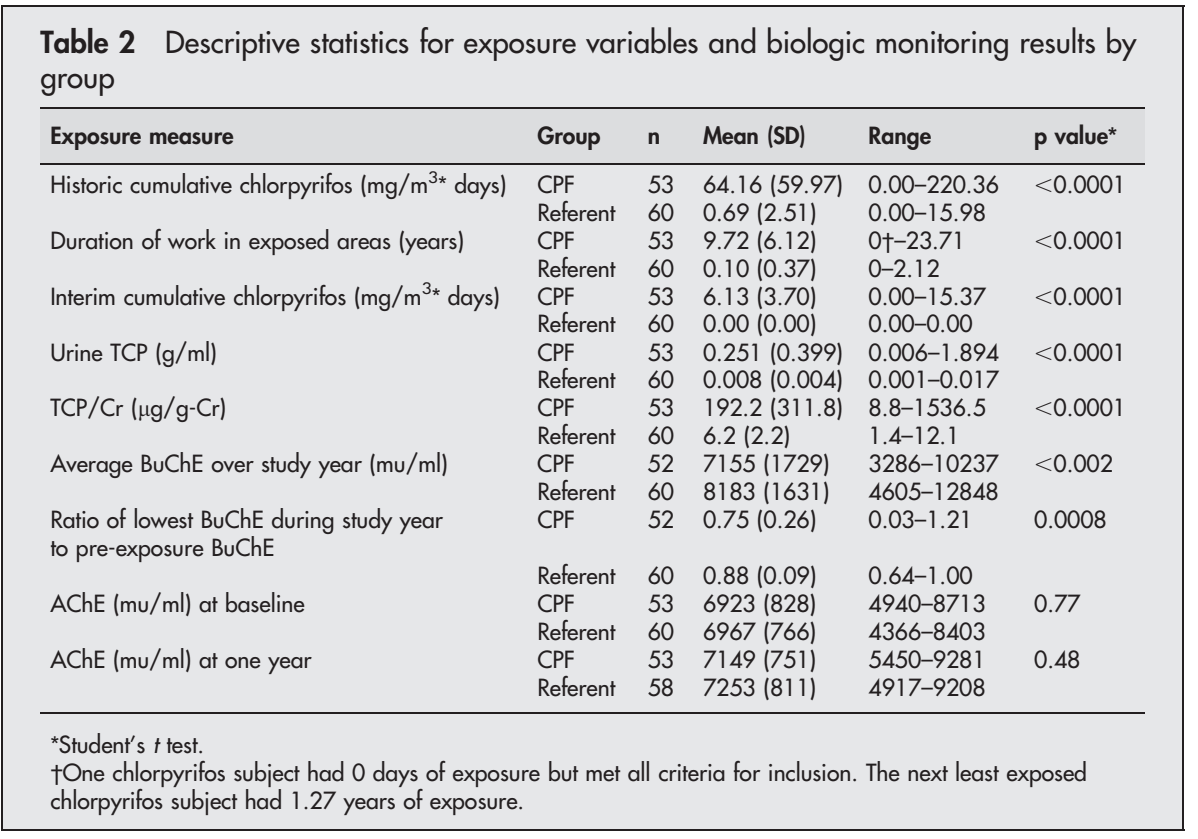

The biological monitoring results showed substantial differences in exposure between the chlorpyrifos group and the referent group for measures of urine TCP/Cr (192.2 v $6.2 \mathrm{ug} / \mathrm{g}-\mathrm{Cr} ; \mathrm{p}<0.0001)$ and average BuChE over the study year $(7155 \vee 8183 \mathrm{mu} / \mathrm{ml} ; \mathrm{p}<0.002)$. Both observations are consistent with exposure to chlorpyrifos among the chlorpyrifos workers. The daily excretion of TCP suggests an estimated daily chlorpyrifos exposure of about 576-627 $\mu \mathrm{g} /$ day, an amount approximately 30\% (range $0-250 \%$ ) of that received by a typical subject exposed during a working day at the permissible exposure level (PEL) of $200 \mu \mathrm{g} / \mathrm{m}^{3}$. AChE activities did not differ significantly between groups, either at the baseline examination $(6923 v 6967 \mathrm{mu} / \mathrm{ml} ; \mathrm{p}=0.77)$ or at the one-year examination $(7149 v 7253 ; \mathrm{p}=0.48)$. The latter results indicate that there was no substantial inhibition of AChE associated with work in the chlorpyrifos exposed areas, compared to work in the referent plant. The estimates of ambient exposure to chlorpyrifos were significantly related to urinary TCP excretion, indicating that the ambient estimates were meaningful for estimating chlorpyrifos exposure among the chlorpyrifos workers. In addition, urine TCP excretion was significantly related to inhibition of BuChE, indicating that the measures of internal dose were meaningful and in the range where well described physiological effects on B-esterases, including BuChE, exist. TCP excretion was unrelated to inhibition of AChE, suggesting that the measures of internal dose are below the range where this physiological effect exists.

\section{Neurological evaluations Symptoms}

At baseline, only two subjects ( 1 chlorpyrifos, 1 referent; $\mathrm{p}>0.99$ ) reported stocking or stocking-glove distribution sensory symptoms. Both subjects described intermittent symptoms. No subject reported persistent sensory or motor symptoms suggestive of neuropathy. Nevertheless, we accepted any symmetrical stocking or stocking-glove sensory symptoms to be suggestive of possible neuropathy. No subject reported persistent extremity weakness. At the one-year evaluation, the two subjects previously reporting intermittent stocking or stocking-glove symptoms at baseline no longer did so. No subject reported persistent extremity weakness at either evaluation.

\section{Signs}

Table 3 summarises the results of the neurological examinations. Few neurological signs potentially consistent with peripheral neuropathy were identified, and the neurological examination results at baseline and at the one-year examination were comparable, with few exceptions. No subject at either examination had clinically detectable weakness, abnormal gait, or abnormal station. At baseline, five subjects ( 2 chlorpyrifos, 3 referent; $p>0.99$ ) had diminished vibration sensation at the great toe, and two subjects (1 chlorpyrifos, I referent; $p>0.99$ ) had diminished touchpressure sensation at the great toe. At the one-year examination, five subjects in the referent group and none in the chlorpyrifos group had diminished vibration sensation $(\mathrm{p}=0.06)$, and one subject (a referent; $\mathrm{p}>0.99)$ had diminished touch-pressure sensation $(p>0.99)$. All sensory abnormalities were described as mild. At baseline, 6 subjects ( 2 chlorpyrifos, 4 referent; $\mathrm{p}=0.68$ ) had decreased or absent ankle reflexes. At the one year examination, 7 subjects (2 chlorpyrifos, 5 referent; $p=0.44$ ) had decreased or absent ankle reflexes.

\section{Nerve conduction studies}

The mean palm temperature at baseline was $33.1^{\circ} \mathrm{C}(32.0-$ $\left.36.5^{\circ} \mathrm{C}\right)$, and the mean ankle temperature was $32.8^{\circ} \mathrm{C}(31.0-$ $\left.35.5^{\circ} \mathrm{C}\right)$. The mean one-year temperatures did not differ significantly from baseline temperatures, and there were no group differences for the palm or ankle temperatures (baseline, one-year, or temperature change over one year). At baseline, no significant group differences existed for any of the NCS measures. All mean values were comparable to published laboratory normal control values based on subjects known to be healthy without underlying disorders associated with neuropathy. ${ }^{20} 28-31$ The mean sural sensory response amplitude was comparable to published control mean values. ${ }^{32}$ No significant differences existed for any of the four summary $\mathrm{Z}$ score measures of motor and sensory amplitude and conduction velocity ( smallest $\mathrm{p}$ value $=0.37$ )

Table 4 shows NCS results comparing chlorpyrifos and referent subjects at the one-year examination and change over one year from baseline. At the one-year examination, there was a single, borderline significant group difference: the peroneal motor distal latency was slightly prolonged 
Table 3 Comparison of neurological symptoms and signs suggestive of peripheral neuropathy for chlorpyrifos (CPF) and referent subjects at baseline (CPF $n=53$; referent $n=60)$ and one-year evaluations (CPF $n=53$; referent $n=58$ )

\begin{tabular}{|c|c|c|c|c|c|c|}
\hline Neurological evaluation & Baseline & No. & p value* & One year & No. & p value* \\
\hline Symptoms of neuropathy & $\begin{array}{l}\text { CPF } \\
\text { Referent }\end{array}$ & 1 & $>0.99$ & $\begin{array}{l}\text { CPF } \\
\text { Referent }\end{array}$ & $\begin{array}{l}0 \\
0\end{array}$ & \\
\hline \multicolumn{7}{|l|}{ Signs of neuropathy } \\
\hline Symmetrical weakness & $\begin{array}{l}\text { CPF } \\
\text { Referent }\end{array}$ & $\begin{array}{l}0 \\
0\end{array}$ & & $\begin{array}{l}\text { CPF } \\
\text { Referent }\end{array}$ & $\begin{array}{l}0 \\
0\end{array}$ & \\
\hline \multicolumn{7}{|l|}{ Sensory signs } \\
\hline Any symmetrical sensory signs & $\begin{array}{l}\text { CPF } \\
\text { Referent }\end{array}$ & $\begin{array}{l}3 \\
4\end{array}$ & $>0.99$ & $\begin{array}{l}\text { CPF } \\
\text { Referent }\end{array}$ & $\begin{array}{l}0 \\
5\end{array}$ & 0.06 \\
\hline \multicolumn{7}{|l|}{ Specific abnormalities } \\
\hline Pin-pain & $\begin{array}{l}\text { CPF } \\
\text { Referent }\end{array}$ & $\begin{array}{l}0 \\
0\end{array}$ & & $\begin{array}{l}\text { CPF } \\
\text { Referent }\end{array}$ & $\begin{array}{l}0 \\
0\end{array}$ & \\
\hline Vibration & $\begin{array}{l}\text { CPF } \\
\text { Referent }\end{array}$ & $\begin{array}{l}2 \\
3\end{array}$ & $>0.99$ & $\begin{array}{l}\text { CPF } \\
\text { Referent }\end{array}$ & $\begin{array}{l}0 \\
5\end{array}$ & 0.06 \\
\hline Joint position & CPF & 0 & & CPF & 0 & \\
\hline Fine touch & CPF & 0 & & $\begin{array}{l}\text { Rererent } \\
\text { CPF } \\
\text { Referent }\end{array}$ & $\begin{array}{l}0 \\
0\end{array}$ & \\
\hline Touch pressure & $\begin{array}{l}\text { CPF } \\
\text { Referent }\end{array}$ & 1 & $>0.99$ & $\begin{array}{l}\text { CPF } \\
\text { Referent }\end{array}$ & $\begin{array}{l}0 \\
1\end{array}$ & $>0.99$ \\
\hline $\begin{array}{l}\text { Abnormal ankle reflexes } \\
\text { Decreased or absent }\end{array}$ & $\begin{array}{l}\text { CPF } \\
\text { Referent }\end{array}$ & 2 & 0.68 & $\begin{array}{l}\text { CPF } \\
\text { Referent }\end{array}$ & $\begin{array}{l}2 \\
5\end{array}$ & 0.44 \\
\hline
\end{tabular}

Table 4 Comparison of nerve conduction study results for chlorpyrifos (CPF) and referent subjects at the one year examination and change over one year from baseline

\begin{tabular}{|c|c|c|c|c|c|c|}
\hline & \multirow[b]{2}{*}{ Group } & \multirow[b]{2}{*}{$\mathbf{n}$} & \multicolumn{2}{|l|}{ One year } & \multicolumn{2}{|l|}{ Change } \\
\hline & & & Mean (SD) & p value* & Mean (SD) & p value* \\
\hline \multicolumn{7}{|l|}{ Median sensory } \\
\hline Amplitude ( $\mu \mathrm{v})$ & $\begin{array}{l}\text { CPF } \\
\text { Referent }\end{array}$ & $\begin{array}{l}53 \\
58\end{array}$ & $\begin{array}{l}32(12.8) \\
33(13.6)\end{array}$ & 0.52 & $\begin{array}{l}2.1(3.8) \\
2.0(5.2)\end{array}$ & 0.91 \\
\hline \multirow{2}{*}{ Terminal CV $(\mathrm{m} / \mathrm{s})$} & CPF & 53 & $52.9(7.0)$ & 0.74 & $-1.9(4.2)$ & 0.93 \\
\hline & Referent & 58 & $53.3(6.7)$ & & $-1.9(4.5)$ & \\
\hline \multirow[t]{2}{*}{ Distal latency (ms) } & CPF & 53 & $3.5(0.5)$ & 0.69 & $0.2(0.22)$ & 0.84 \\
\hline & Referent & 58 & $3.5(0.5)$ & & $0.2(0.21)$ & \\
\hline \multicolumn{7}{|l|}{ Ulnar sensory } \\
\hline \multirow[t]{2}{*}{ Amplitude ( $\mu \mathrm{v})$} & CPF & 53 & 30 (12.3) & 0.68 & $3.0(6.0)$ & 0.65 \\
\hline & Referent & 58 & $31(14.5)$ & & $3.6(7.1)$ & \\
\hline \multirow{2}{*}{ Terminal CV $(\mathrm{m} / \mathrm{s})$} & CPF & 53 & $55.3(5.5)$ & 0.75 & $-2.2(4.4)$ & 0.71 \\
\hline & Referent & 58 & $54.9(5.2)$ & & $-2.5(4.2)$ & \\
\hline \multirow[t]{2}{*}{ Distal latency (ms) } & CPF & 53 & $3.3(0.3)$ & 0.97 & $0.1(0.2)$ & 0.80 \\
\hline & Referent & 58 & $3.3(0.3)$ & & $0.1(0.2)$ & \\
\hline \multicolumn{7}{|l|}{ Sural sensory } \\
\hline \multirow[t]{2}{*}{ Amplitude ( $\mu \mathrm{v})$} & CPF & 53 & $20(8.2)$ & 0.20 & $2.1(6.2)$ & 0.09 \\
\hline & Referent & 58 & $18(6.8)$ & & $0.1(6.4)$ & \\
\hline \multirow[t]{2}{*}{ Terminal CV $(\mathrm{m} / \mathrm{s})$} & CPF & 53 & $48.6(4.7)$ & 0.34 & $-1.8(5.1)$ & 0.70 \\
\hline & Referent & 58 & $47.7(4.7)$ & & $-2.2(4.1)$ & \\
\hline \multirow[t]{2}{*}{ Distal latency (ms) } & CPF & 53 & $3.7(0.3)$ & 0.50 & $0.2(0.3)$ & 0.82 \\
\hline & Referent & 58 & $3.7(0.3)$ & & $0.2(0.3)$ & \\
\hline \multicolumn{7}{|l|}{ Median motor } \\
\hline \multirow[t]{2}{*}{ Amplitude (mv) } & CPF & 53 & 10.9 (3.2) & 0.81 & $1.5(2.7)$ & 0.08 \\
\hline & Referent & 58 & $10.7(3.4)$ & & $0.6(2.5)$ & \\
\hline \multirow[t]{2}{*}{ Forearm CV $(\mathrm{m} / \mathrm{s})$} & CPF & 53 & $55.5(3.9)$ & 0.63 & $-1.2(3.4)$ & 0.18 \\
\hline & Referent & 58 & $55.1(3.6)$ & & $-2.0(3.5)$ & \\
\hline \multirow[t]{2}{*}{ Distal latency (ms) } & CPF & 53 & $3.8(0.6)$ & 0.57 & $0.3(0.3)$ & $>0.99$ \\
\hline & Referent & 58 & $3.7(0.6)$ & & $0.3(0.3)$ & \\
\hline \multirow[t]{2}{*}{$\mathrm{F}$ wave latency (ms) } & CPF & 53 & $28.3(2.1)$ & 0.92 & $0.5(0.9)$ & 0.69 \\
\hline & Referent & 58 & $28.3(2.5)$ & & $0.6(1.4)$ & \\
\hline \multicolumn{7}{|l|}{ Peroneal motor } \\
\hline \multirow[t]{2}{*}{ Amplitude (mv) } & CPF & 53 & $6.3(2.7)$ & 0.83 & $-1.0(2.1)$ & 0.81 \\
\hline & Referent & 58 & $6.4(2.4)$ & & $-1.1(1.7)$ & \\
\hline \multirow[t]{2}{*}{ Distal latency (ms) } & CPF & 52 & $4.9(0.8)$ & 0.07 & $0.2(0.6)$ & 0.18 \\
\hline & Referent & 58 & $4.6(0.6)$ & & $0.1(0.3)$ & \\
\hline \multirow[t]{2}{*}{$\mathrm{F}$ wave latency (ms) } & CPF & 50 & $49.2(3.8)$ & 0.22 & $0.7(1.9)$ & 0.18 \\
\hline & Referent & 58 & $50.3(5.2)$ & & $1.4(2.9)$ & \\
\hline
\end{tabular}

${ }^{*} t$ test for difference in means (adjusted for unequal variance between groups)

$\mathrm{CV}$, conduction velocity. 
among the chlorpyrifos subjects compared to the referents (4.6 $v 4.9 \mathrm{~ms}, \mathrm{p}=0.07$ ). Compared to baseline, the one-year NCS results showed many substantial changes, characterised primarily by increased sensory response amplitudes and decreased sensory and motor conduction velocities. However, the change over time was comparable in both groups, and all mean values remained comparable to published laboratory normal control values. The only borderline significant group differences between the baseline and the one-year examination involved a larger increase in the median motor and sural sensory amplitudes (indicating better performance) among the chlorpyrifos subjects compared to the referent subjects ( $1.5 v 0.6 \mathrm{mv} ; \mathrm{p}=0.08$ and $2.1 \quad v \quad 0.1 \mu \mathrm{v} ; \mathrm{p}=0.09$, respectively). There were no significant group differences for any of the four summary $\mathrm{Z}$ scores (motor and sensory amplitude and motor and sensory conduction velocity) at baseline, one year, or for the change over one year. At baseline and at the one-year examination, 4 subjects (1 chlorpyrifos, 3 referent; $p=0.62$ ) had at least one NCS abnormality in two different nerves, fulfilling the electrodiagnostic criteria for a diffuse or multifocal neuropathy.

\section{Neuropathy outcome variables}

Table 5 summarises the number of subjects fulfilling the different diagnostic categories of neuropathy at the baseline and one-year evaluations. At baseline, two subjects (one in each group) had evidence of subclinical neuropathy. Eleven subjects ( 4 chlorpyrifos, 7 referent; $\mathrm{p}=0.50$ ) had possible neuropathy. Two subjects ( 1 chlorpyrifos, 1 referent; $\mathrm{p}>0.99$ ) had two appropriate abnormalities among sensation and reflexes fulfilling criteria for probable neuropathy. Two subjects (both in the referent group) had confirmed neuropathy. None of the subjects with probable neuropathy or confirmed neuropathy reported symptoms of neuropathy, and all of them had signs described as mild or equivocal. Both subjects with confirmed neuropathy showed decreased touch pressure sensation in the feet (described as equivocal), normal ankle reflexes, and borderline-low conduction velocities with normal sural response amplitude. Both were tall (near $1.9 \mathrm{~m}$ ), heavy (over $105 \mathrm{~kg}$ ), and had an increased BMI (over 30). The neurologist attributed the equivocal abnormalities to body size for both subjects, as diminished sensation in large individuals is a common finding that likely reflects the distribution of a fixed number of mechanoreceptors over a surface area that is larger than normal. ${ }^{22}$

At the one-year examination, two subjects (one in each group; $\mathrm{p}>0.99$ ) had subclinical neuropathy. Eight subjects (2 chlorpyrifos, 6 referent; $\mathrm{p}=0.28$ ) had possible neuropathy. Two subjects (both referents, $\mathrm{p}=0.50$ ) fulfilled criteria for probable neuropathy, and two additional subjects (both referents; $\mathrm{p}=0.50$ ) had confirmed neuropathy. None of the subjects with probable neuropathy or confirmed neuropathy reported symptoms of neuropathy, and all four subjects had signs described as mild or equivocal. One of the two referent subjects with confirmed neuropathy had decreased touch pressure sensation in the feet (mild or equivocal impairment) and normal ankle reflexes. The other subject had absent ankle reflexes. Both showed borderline-low conduction velocities with normal or borderline-low sural response amplitudes. One of these subjects was tall and had an increased BMI. The neurologist attributed the mild clinical abnormalities to body size for this subject, who also had confirmed neuropathy at baseline. The remaining subject with confirmed neuropathy had an identifiable systemic medical explanation for the mild neuropathy that was unrelated to potential chlorpyrifos exposure. This subject also was using a medication with potential peripheral neurotoxicity and had fulfilled criteria for possible neuropathy at the baseline examination. One referent subject who had confirmed neuropathy at baseline (attributed to large body size and based on equivocal or borderline NCS abnormalities) continued to fulfil criteria for possible neuropathy at one year, but only showed NCS abnormality in one nerve at the oneyear examination.

\section{Longitudinal analyses}

Table 6 summarises the results of the longitudinal logistic regression analyses for the neurological examination and peripheral neuropathy outcomes. The odds ratios for developing symptoms of neuropathy or conventional clinical signs of neuropathy did not differ significantly among chlorpyrifos subjects at baseline or after one year of additional potential exposure to chlorpyrifos compared to the referent group at baseline. Similarly, the odds ratios for developing any diagnosable level of peripheral neuropathy (subclinical, possible, probable, or confirmed) were not significantly increased among the chlorpyrifos subjects at either of the two examination times compared to the referent group at baseline.

Table 7 shows the results of the mixed linear modelling. We were primarily interested in the interaction term between group and time in order to determine whether chlorpyrifos exposure affected NCS results over time. Although no significant differences were shown between the chlorpyrifos group and the referent group pooled over the two examinations, numerous significant differences existed among all subjects combined between the baseline and one-year examinations. There were no significant and only two borderline significant group-by-time interactions. The median motor amplitude group-by-time interaction $(p=0.08)$ showed increased amplitude over time (better performance) for both groups, but chlorpyrifos subjects improved more than referent subjects did. The peroneal distal latency groupby-time interaction $(p=0.08)$ showed a significant three way interaction between height, group, and time. Chlorpyrifos subjects who were taller had longer peroneal distal latencies (worse performance) than did subjects who were shorter.

Table 5 Comparison of neurological outcome variable results related to peripheral neuropathy for chlorpyrifos (CPF) and referent subjects at baseline (CPF $n=53$; referent $n=60)$ and one-year evaluations (CPF $n=53$; referent $n=58$ )

\begin{tabular}{lllllll}
\hline Diagnostic categoriest & Baseline & No. & p value* & One year & No. & p value* \\
\hline Subclinical neuropathy & CPF & 1 & $>0.99$ & CPF & 1 & $>0.99$ \\
& Referent & 1 & & Referent & 1 & \\
Possible neuropathy & CPF & 4 & 0.50 & CPF & 2 & 0.28 \\
& Referent & 7 & & Referent & 6 & \\
Probable neuropathy & CPF & 1 & $>0.99$ & CPF & 0 & 0.50 \\
& Referent & 1 & & Referent & 2 & \\
Confirmed neuropathy & CPF & 0 & 0.50 & CPF & 0 & 0.50 \\
& Referent & 2 & & Referent & 2 & \\
\hline
\end{tabular}

*Fisher's exact test or $\chi^{2}$ test.

†See text for definitions and diagnostic criteria. 
Table 6 Results of longitudinal analysis for clinical neurological outcomes related to peripheral neuropathy $(n=113)$

\begin{tabular}{|c|c|c|c|c|c|}
\hline Outcome & No.* & ORt & $\begin{array}{l}\text { OR (group) } \\
\text { (CPF at baseline) }\end{array}$ & $\begin{array}{l}\text { OR (time) (referent } \\
\text { at one year) }\end{array}$ & $\begin{array}{l}\text { OR (group*time) } \\
\text { (CPF at one year) }\end{array}$ \\
\hline \multicolumn{6}{|l|}{ Neurological evaluation } \\
\hline Symptoms of neuropathy $\ddagger$ & 2 & 1.00 & $1.13(0.01,90.55)$ & $1.03(0,40.34)$ & $\S$ \\
\hline Symmetrical sensory signs $\ddagger$ & 12 & 1.00 & $0.84(0.12,5.24)$ & $1.32(0.27,7.01)$ & $0.29(0,113.48)$ \\
\hline Trace or absent ankle reflexes & 13 & 1.00 & $0.55(0.10,3.13)$ & $1.32(0.82,2.12)$ & $0.55(0.10,3.13)$ \\
\hline \multicolumn{6}{|l|}{ Diagnostic categories } \\
\hline Subclinical neuropathy & 4 & 1.00 & $1.13(0.07,18.60)$ & $1.04(0.06,17.37)$ & $1.13(0.70,18.60)$ \\
\hline Possible neuropathy & 19 & 1.00 & $0.62(0.17,2.24)$ & $0.87(0.41,1.87)$ & $0.30(0.06,1.50)$ \\
\hline Probable neuropathy $\ddagger$ & 4 & 1.00 & $1.13(0.01,90.55)$ & $2.09(0.11,126.39)$ & $\S$ \\
\hline Confirmed neuropathy $\ddagger$ & 4 & 1.00 & $0.46(0,6.02)$ & $1.04(0.07,14.74)$ & $\S$ \\
\hline \multicolumn{6}{|c|}{$\begin{array}{l}\text { *Total number of positive responses at baseline and at one year. } \\
\text { †Referent group at baseline. } \\
\text { †Approximate odds ratios using repeated measures logistic regression with the normal distribution on sparse data. } \\
\text { §Not estimable due to small number of abnormalities (complete or partial separation). } \\
\text { - See text for definitions and diagnostic criteria. }\end{array}$} \\
\hline
\end{tabular}

There were three additional outcomes for which the groupby-time interaction was not significant or borderline, yet a three way interaction between a covariate, group, and time was significant. Anxiety level significantly influenced the group-by-time interaction for median motor distal latency $(\mathrm{p}=0.03)$ such that chlorpyrifos subjects with high anxiety had longer distal latencies (worse performance) than did subjects with low anxiety. Anxiety did not substantially affect the group-by-time interaction for referent subjects. Body mass index significantly influenced the group-by-time interaction for median $\mathrm{F}$ wave latency $(\mathrm{p}=0.03)$. Chlorpyrifos subjects with high BMI had longer latencies (worse performance) than did subjects with low BMI, while referents showed the opposite effect. Leg temperature significantly influenced the group-by-time interaction for peroneal $\mathrm{F}$ wave latency $(\mathrm{p}=0.02)$. Chlorpyrifos subjects who had higher leg temperature had shorter latencies (better performance) compared to subjects who had lower leg temperature.

\section{DISCUSSION}

We found no support for the hypothesis that workers with chronic occupational exposure to chlorpyrifos during the manufacturing process develop either clinically evident peripheral neuropathy or subclinical NCS abnormalities compared to referents. We also found no evidence of clinical or subclinical deterioration among the chlorpyrifos subjects over one year of additional chlorpyrifos exposure. At the oneyear examination, one borderline significant nerve conduction group difference existed. Namely, the peroneal motor distal latency was slightly prolonged among chlorpyrifos subjects compared to referents (4.9 $v 4.6 \mathrm{~ms}, \mathrm{p}=0.07)$. Although prolonged distal latencies may be among the earliest manifestations of a toxic axonopathy, we believe this observation is unimportant for several reasons. First, the group mean peroneal latencies were all well within the normal range, and they did not differ significantly at baseline $(p=0.45)$ or show significant change over one year $(p=0.18)$. Second, none of the other distal latencies or the

Table 7 Parameter estimates and $p$ values for longitudinal analyses of nerve conduction results by group modelled as a function of group, time, group-time interaction, covariates, ${ }^{*}$ and significant three-way interactions using a stepwise selection procedure $(n=113)$

\begin{tabular}{|c|c|c|c|}
\hline & Group (p value) & Time (p value) & Group*time (p value) \\
\hline \multicolumn{4}{|l|}{ Median sensory } \\
\hline Amplitude ( $\mu \mathrm{v})$ & $-2.41(0.13)$ & $2.26(<0.01)$ & $-0.09(0.91)$ \\
\hline Terminal CV $(\mathrm{m} / \mathrm{s})$ & $-0.64(0.51)$ & $-2.34(<0.01)$ & $-0.09(0.91)$ \\
\hline Distal latency (ms) & $0.03(0.65)$ & $0.19(<0.01)$ & $0.01(0.88)$ \\
\hline \multicolumn{4}{|l|}{ Ulnar sensory } \\
\hline Amplitude $(\mu \mathrm{v})$ & $-1.20(0.30)$ & $3.72(<0.01)$ & $-0.68(0.59)$ \\
\hline Terminal CV $(\mathrm{m} / \mathrm{s})$ & $-0.05(0.91)$ & $-2.98(<0.01)$ & $0.28(0.73)$ \\
\hline Distal latency (ms) & $0.01(0.78)$ & $0.15(<0.01)$ & $0.01(0.88)$ \\
\hline \multicolumn{4}{|l|}{ Sural sensory } \\
\hline Amplitude $(\mu v)$ & $-0.65(0.75)$ & $0.24(0.04)$ & $1.97(0.10)$ \\
\hline Terminal CV $(\mathrm{m} / \mathrm{s})$ & $0.41(0.34)$ & $-2.55(<0.01)$ & $0.39(0.66)$ \\
\hline Distal latency (ms) & $-0.05(0.26)$ & $0.21(<0.01)$ & $0.01(0.84)$ \\
\hline \multicolumn{4}{|l|}{ Median motor } \\
\hline Amplitude (mv) & $-0.71(0.63)$ & $0.61(<0.01)$ & $0.87(0.08)$ \\
\hline Forearm CV $(\mathrm{m} / \mathrm{s})$ & $-0.61(0.65)$ & $-1.88(<0.01)$ & $0.72(0.28)$ \\
\hline Distal latency (ms) & $0.09(0.31)$ & $0.39(<0.01)$ & $-0.01(0.88)$ \\
\hline $\mathrm{F}$ wave latency (ms) & $0.34(0.26)$ & $0.6(<0.01)$ & $-0.09(0.68)$ \\
\hline \multicolumn{4}{|l|}{ Peroneal motor } \\
\hline Amplitude (mv) & $-0.16(0.82)$ & $-1.15(<0.01)$ & $0.08(0.82)$ \\
\hline Distal latency (ms) & $0.1(0.11)$ & $0.09(<0.01)$ & $0.16(0.08)$ \\
\hline $\mathrm{F}$ wave latency (ms) & $0.31(0.99)$ & $1.39(<0.01)$ & $-0.62(0.19)$ \\
\hline \multicolumn{4}{|l|}{ Summary Z scores } \\
\hline Motor amplitude & $-0.27(0.64)$ & $-0.14(0.98)$ & $0.28(0.18)$ \\
\hline Motor conduction & $-0.57(0.37)$ & $-0.08(0.85)$ & $0.21(0.52)$ \\
\hline Sensory amplitude & $-0.35(0.41)$ & $-0.01(0.44)$ & $0.2(0.37)$ \\
\hline Sensory conduction & $-0.02(0.72)$ & $0.15(0.93)$ & $-0.24(0.68)$ \\
\hline
\end{tabular}

*Potential covariates included age, height, weight, sex, body mass index, temperature over nerve being tested education level, anxiety, smoking pack-years, and estimated general ability. 
motor conduction summary $\mathrm{Z}$ score showed a significant group difference. The few subjects who had confirmed neuropathy were all in the referent group. The clinical endpoints used to define "neuropathy" utilised conventional signs of symmetric, stocking-glove distribution sensory loss or ankle reflex abnormalities. A diagnosis of definite neuropathy required electrodiagnostic confirmation based on NCS abnormality in two anatomically distinct nerves. ${ }^{21} 3334$ The unremarkable neurological examinations and NCS results are important in assuring that no clinically important peripheral impairments were overlooked among these subjects.

Similarly, the longitudinal logistic regression analyses found no evidence that potential chlorpyrifos exposure increased the risk of developing clinically evident neuropathy among chlorpyrifos workers either at baseline or after one year of additional exposure compared to the referent group at baseline. The mixed regression models with repeated measures used to investigate subclinical group-by-time interactions among the NCS measures identified several interesting interactions, but only a few of them could be related to potential chlorpyrifos exposure. The most prominent interactions involved time, and changes that occurred between the baseline and one-year examinations were similar for both groups, reflecting a common systematic difference involving all subjects.

The combination of increased amplitude and decreased conduction speed suggests a temperature effect, not a neurotoxic effect. ${ }^{35}$ It is our hypothesis that the warming protocol successfully reproduced surface temperatures for individual subjects to within $0.5^{\circ} \mathrm{C}$ of the baseline measures, but apparently did not reproduce near-nerve temperatures to the same standard. A discrepancy between surface and nearnerve temperature may result from the warming protocol, as surface temperatures only approximate the nerve-nerve temperatures. ${ }^{36}$ Near-nerve and surface temperatures differ for many reasons, and the relation varies to some extent among individuals. ${ }^{36}$ Many subjects required little or no warming at the one-year examination, and several subjects had temperatures greater than at baseline and were permitted to cool. Why this occurred is unknown, but it may have been due to anxiety about the clinical evaluation at the baseline examination. ${ }^{37}{ }^{38}$ Apprehensive subjects who have cool, sweaty hands and feet due to autonomic nervous system stimulation typically require warming. It is possible that our subjects were less apprehensive the second time they were examined than they were at the baseline examination. A difference in near-nerve temperatures of about $1{ }^{\circ} \mathrm{C}$ between the two examinations would explain the changes. $^{28}{ }^{29}{ }^{39-41}$ The possibility of an inadvertent temperature bias highlights the importance of using a referent group. NCS results similar to ours were reported by Datsov, ${ }^{42}$ who evaluated OP insecticide applicators at the beginning and the end of the spraying season. Decreased motor conduction velocity was attributed to exposure, but a concurrent increase in response amplitude suggests that decreased temperature, not a neurotoxic effect, likely explains the findings.

The group-by-time interactions we report were important in deciding whether chlorpyrifos exposure influenced NCS results. No significant group-by-time interactions were identified, and the few borderline significant associations showed minor effects varying in direction. The interactions between NCS results and height, BMI, and leg temperature are consistent with known influences of these covariates on electrophysiological measures. ${ }^{29} 43$

Our study has several strengths, including the longitudinal design and the opportunity to compare workers who had measurable occupational chlorpyrifos exposure to other workers of comparable demographic characteristics but who had no such exposure. Participation of exposed and of referent subjects was excellent. Among the exposed subjects, exposure was substantial. Based on TCP excretion, daily exposure estimates were in the range of a few hundred micrograms per day, about three orders of magnitude higher than the estimates in household exposures derived from the study of Pang and colleagues, ${ }^{44}$ and approximately 30\% of what would be received by a worker exposed during a working day at the PEL of $200 \mu \mathrm{g} / \mathrm{m}^{3}$. The subject in our study who had the highest urine TCP excretion was estimated to have daily chlorpyrifos exposure of approximately $250 \%$ of the PEL. The exposures (estimated from the urine TCP/Cr) were in the range where well described physiological effects on B-esterases exist, and these were conformed by evidence of BuChE inhibition. Fifteen of 52 chlorpyrifos subjects (29\%) had a greater than $40 \%$ reduction in BuChE, based on the minimum BuChE during the study compared to their preexposure BuChE. Thus, our study was conducted in a setting where the exposures were associated with appreciable reductions in cholinesterase activity in a sizeable proportion of the study population. We used standard clinical outcome variables with known sensitivity and specificity, ${ }^{34}$ and NCS measures with established reliability and precision..$^{45-47}$ This precision permits identification of changes in NCS performance due to factors such as the effects of temperature. The combined clinical and electrodiagnostic endpoints are unambiguous, and they have known meaning in the context of clinical medicine.

It could be argued that we did not follow subjects long enough to identify an interval deterioration. However, we had sufficient power to detect small changes in the sural response amplitude, a measure generally considered the most sensitive indicator of a sensory neuropathy. In fact, within the spectrum of patients with clinically evident sensory or sensorimotor neuropathies, few have recordable sural responses, let alone sural response amplitude within the normal range. No subject we examined had an undetectable or low amplitude sural response.

We did not perform needle electromyography examinations (NEE), but the NEE is less likely to identify early subclinical group differences in longitudinal or population studies compared to the more quantitative nerve conduction measures. ${ }^{48}$ Recent cross-sectional studies of workers exposed to OP pesticides ${ }^{49}$ found sensory abnormalities more often than motor deficits, and only non-specific, subjective increases in polyphasic potentials on NEE, without fibrillation potentials or positive waves, the earliest and most objective indicators of ongoing or previous motor nerve degeneration. Nevertheless, the peripheral nervous system has substantial regenerative capabilities, and small neurotoxic effects could be balanced by ongoing regeneration of sensory or motor axons.

We also feel it is unlikely that we missed evidence of subclinical neuropathy manifest by slowing of motor conduction of the type reported by Misra and colleagues. ${ }^{50}$ Although, in their evaluation of OP exposed sprayers, they reported that AChE activities showed a significant exposure effect, suggesting exposure levels were greater than encountered by our subjects. Subclinical neuropathy represents a form of asymptomatic neuropathy that has not yet produced clinically evident signs but that is inferred by abnormality on some type of sensitive testing such as NCS. The fact that NCS results in our study were similar for the CPF and referent groups and comparable to published normal values ${ }^{20} 29$ argues strongly against the presence of a subclinical neuropathy among these workers with long term occupational exposure to chlorpyrifos.

While our study was being conducted, Jamal and colleagues reported that their evaluation of sheep farmers 
and dippers associated a chronic, predominately sensory neuropathy with exposure to OP pesticides. ${ }^{49}$ The neuropathy was atypical of most toxic neuropathies, in general, and of reports of OP induced neuropathy, in particular, as it involved small fibres more than large fibres. In contrast, subtle vibration threshold abnormalities suggestive of large fibre neuropathy have been reported among farmers and applicators exposed to OP pesticides compared with matched population controls, ${ }^{51}$ and among subjects with previous acute OP pesticide poisoning. ${ }^{52}$ The evidence supporting a small fibre neuropathy was based on thermal threshold determinations, and only four of the 23 subjects classified with probable or definite neuropathy had neurological signs of neuropathy. ${ }^{49}$ We did not perform quantitative sensory testing (QST), a potentially useful tool for measuring sensory impairment among patients with neuropathy. However, QST is subject to non-organic influences, and QST results should not be the sole criterion to diagnose pathology. ${ }^{53}$ None of the subjects we studied was symptomatic for a large or small fibre neuropathy, and there were no clinical signs of impaired pin-pain sensation. Jamal and colleagues also associated an increasing severity of neuropathy with anxiety and depression, as measured by neuropsychological tests, and Salvi and colleagues $^{54}$ reported that 13 of 37 OP pesticide exposed agricultural workers had a generalised anxiety disorder (unblinded cross-sectional evaluation). The present analyses do not address neuropsychological performance, but anxiety levels as measured by the Brief Symptom Inventory were comparable for the chlorpyrifos and referent subjects at baseline. We are evaluating further the effects of chlorpyrifos exposure on the central nervous system and behaviour, and those results will be reported separately. However, the exposures we have described were to a single OP insecticide, without substantial exposure to other neurotoxicants. Our results do not preclude the possibility that exposure to mixtures of OP compounds under different circumstances may have effects that we did not observe.

In summary, we found no support for the hypothesis that chronic chlorpyrifos exposure during the manufacturing process sufficient to produce biological effects on BuChE activity is associated with clinically evident or subclinical peripheral neuropathy among chlorpyrifos subjects compared to referents after one year of additional exposure.

\section{ACKNOWLEDGEMENTS}

We wish to acknowledge the additional investigators on this project, including B Gillespie, B Giordani, S P Levine, J Raz (deceased); and other members of the Neurobehavioral Toxicology Program Chlorpyrifos Study team: J N Baughman, Z Li, and J A Wolfe. We wish to acknowledge receipt of a SPHERE (Supporting Public Health and Environmental Research Efforts) Award from the Dow Chemical Company Foundation, for which the authors wish to express their gratitude. We also wish to acknowledge the assistance provided to us by the many Dow Chemical Company and Dow AgroSciences employees who assisted at various points in supporting this research. Finally, we are indebted to the Dow Chemical Company employees who volunteer their time as subjects in this study.

This study was financially supported by Dow AgroSciences, Indianapolis, Indiana, USA, with additional support from Dow Chemical Company and Dow Chemical Company Foundation.

\footnotetext{
Authors' affiliations

J W Albers, Department of Neurology, University of Michigan, USA

D H Garabrant, R P Garrison, R J Richardson, Department of

Environmental Health Sciences, University of Michigan, USA

S J Schweitzer, Department of Biostatistics, University of Michigan, USA S Berent, Department of Psychiatry, University of Michigan, USA

Disclosure: Some of the authors have at times been retained as consultants or served as expert witnesses in litigation for firms or companies, including Dow Chemical Company and Dow AgroSciences,
}

concerned with the manufacture or use of insecticides. Support of these activities has included both personal and institutional remuneration

\section{REFERENCES}

1 Ray DE. Pesticide neurotoxicity in Europe: real risks and perceived risks. Neurotoxicology 2000;21:219-21.

2 Kropp TJ, Richardson RJ. Relative inhibitory potencies of chlorpyrifos oxon, chlorpyrifos methyl oxon, and mipafox for acetylcholinesterase versus neuropathy target esterase. J Toxicol Environ Health 2003;66:1145-57.

3 Richardson RJ. Assessment of the neurotoxic potential of chlorpyrifos relative to other organophosphorus compounds: a critical review of the literature. $J$ Toxicol Environ Health 1995;44:135-65.

4 Lotti M. The pathogenesis of organophosphate polyneuropathy. Crit Rev Toxicol 1991;21:465-87.

5 Richardson RJ, Moore TB, Kayyali US, et al. Inhibition of hen brain acetylcholinesterase and neurotoxic esterase by chlorpyrifos in vivo and kinetics of inhibition by chlorpyrifos oxon in vitro: application to assessment of neuropathic risk. Fundam Appl Toxicol 1993;20:273-9.

6 Levin ED, Addy N, Baruah A, et al. Prenatal chlorpyrifos exposure in rats causes persistent behavioral alterations. Neurotoxicol Teratol 2002;24:733-41.

7 Kaplan JG, Rosenberg NL, Pack D, et al. Sensory neuropathy associated with Dursban (chlorpyrifos) exposure. Neurology 1993;43:2193-6.

8 Pilkington A, Buchanan D, Jamal GA, et al. An epidemiological study of the relations between exposure to organophosphate pesticides and indices of chronic peripheral neuropathy and neuropsychological abnormalities in sheep farmers and dippers. Occup Environ Med 2001;58:702-10.

9 Linz DH, Suskind RR, Lockey JE, et al. Health status of pesticide applicators with attention to the peripheral nervous system. J Argomed 1994;1:23-42.

10 Beach JR, Spurgeon A, Stephens R, et al. Abnormalities on neurological examination among sheep farmers exposed to organophosphorous pesticides. Occup Environ Med 1996:53:520-5.

11 Engel LS, Keifer MC, Checkoway H, et al. Neurophysiological function in farm workers exposed to organophosphate pesticides. Arch Environ Health 1998;53:7-14.

12 Moretto A, Lotti M. Poisoning by organophosphorus insecticides and sensory neuropathy. J Neurol Neurosurg Psychiatry 1998;64:463-8.

13 Ray DE, Richards PG. The potential for toxic effects of chronic, low-dose exposure to organophosphates. Toxicol Lett $2001 ; 120: 343-51$.

14 Lotti M. Low-level exposures to organophosphorus esters and peripheral nerve function. Muscle Nerve 2002;25:492-504.

15 Dow Elanco. Chlorpyrifos exposure and human health. Final report of an independent panel of scientists convened by DowElanco in cooperation with the US Environmental Protection Agency. Panel report. Indianapolis: Dow Elanco, 1997.

16 Albers JW, Cole P, Greenberg RS, et al. Analysis of chlorpyrifos exposure and human health: expert panel report. J Toxicol Environ Health 1999;2:301-24.

17 Woods HF, and the Working Group on Organophosphates. Organophosphates. Committee on Toxicity of Chemicals in Food, Consumer Products and the Environment. UK, 1999:1-7.

18 Albers JW, Cavender GF, Levine SP, et al. Asymptomatic sensorimoto polyneuropathy in workers exposed to elemental mercury. Neurology 1982;32: 1168-74

19 Diabetes Control and Complications Trial (DCCT) Research Group. Effect of intensive diabetes treatment on nerve conduction in the Diabetes Control and Complications Trial. Ann Neurol 1995;38:869-80.

20 Salerno DF, Franzblau A, Werner RA, et al. Median and ulnar nerve conduction studies among workers: normative values. Muscle Nerve 1998;21:999-1005

21 Dyck PJ. Detection, characterization, and staging of polyneuropathy: assessed in diabetes. Muscle Nerve 1988;11:21-32.

22 Dyck PJ, Litchy WJ, Lehman KA, et al. Variables influencing neuropathic endpoints: the Rochester Diabetic Neuropathy Study of Healthy Subjects. Neurology 1995;45:1115-21.

23 Albers JW, Wald JJ, Werner RA, et al. Absence of polyneuropathy among workers previously diagnosed with solvent-induced toxic encephalopathy. J Occup Environ Med 1999:41:500-9.

24 Blair JR, Spreen O. Predicting premorbid IQ: a revision of the North American Adult Reading Test. Clin Neuropsychol 1989;3:2, 129-36.

25 Derogatis LR, Spenser PM. Brief Symptom Inventory (BSI). Baltimore: Johns Hopkins University School of Medicine, 1982

26 Butschek DS, Miller GE. The relationship of cognitively induced anxiety and hand temperature reduction. J Psychosom Res 1980;24:131-6.

27 Crawford DG, Friesen DD, Tomlinson-Keasey C. Effects of cognitively induced anxiety on hand temperature. Biofeedback Self Regul 1977;2:139-46.

28 Letz R, Gerr F. Covariates of human peripheral nerve function: I-nerve conduction velocity and amplitude. Neurotoxicol Teratol 1994;16:95-104.

29 Stetson DS, Albers JW, Silverstein BA, et al. Effects of age, sex, and anthropometric factors on nerve conduction measures. Muscle Nerve 1992; 15:1095-104.

30 Greene DA, Sima AF, Pfeifer MA, et al. Diabetic neuropathy. Ann Rev Med 1990:41:303-17.

31 Robinson LR, Micklesen BS, Wang L. Strategies for analyzing nerve conduction data: superiority of a summary index over single tests. Muscle Nerve 1998;21:1166-71.

32 Wilbourn AJ. Sensory nerve conduction studies. J Clin Neurophysiol $1994 ; 11: 584-601$. 
33 Dyck PJ, O'Brien PC. Meaningful degrees of prevention or improvement of nerve conduction in controlled clinical trials of diabetic neuropathy. Diabetes Care 1989;12:649-52.

34 The Diabetes Control and Complications Trial Research Group. The effect of intensive treatment of diabetes on the development and progression of longterm complications in insulin-dependent diabetes mellitus. N Engl J Med 1993;329:977-86.

35 Denys EH. The influence of temperature in clinical electrophysiology. Muscle Nerve 1991; 14:795-811.

36 Rutkove SB. Effects of temperature on neuromuscular electrophysiology. Muscle Nerve 2001;24:867-82.

37 Kothari MJ, Preston DC, Plotkin GM, et al. Electromyography: do the diagnostic ends justify the means? Arch Phys Med Rehabil 1995;76:947-9.

38 Jan MM, Schwartz M, Benstead TJ. EMG related anxiety and pain: a prospective study. Can J Neurol Sci 1999;26:294-7.

39 Dioszeghy $\mathbf{P}$, Stalberg E. Changes in motor and sensory nerve conduction parameters with temperature in normal and diseased nerve. Electroencephalogr Clin Neurophysiol 1992;85:229-35.

40 Bolton CF, Carter KM. Human sensory nerve compound action potential amplitudes: variation with sex and finger circumference. J Neurol Neurosurg Psychiatry 1980;43:925-8.

41 Nelson KR, Rivner MH. Electromyography and nerve conduction laboratory in clinical neurologic practice. Semin Neurol 1990;10:131-40.

42 Datsov $\mathbf{E}$. An electroneurographic study of agricultural workers working with organophosphate pesticides [in Bulgarian]. Problemi na Khigienata 1990;15:55-61.

43 Rivner MH, Swift TR, Malik K. Influence of age and height on nerve conduction. Muscle Nerve 2001;24:1134-41.
44 Pang Y, Maclntosh DL, Camann DE, et al. Analysis of aggregate exposure to chlorpyrifos in the NHEXAS-Maryland investigation. Environ Health Perspect 2002; 110:235-40.

45 Redmond JMT, McKenna MJ, Feingold M, et al. Sensory testing versus nerve conduction velocity in diabetes polyneuropathy. Muscle Nerve 1992;15:1334-9.

46 Dyck PJ, Karnes JL, O'Brien PC, ef al. The Rochester Diabetic Neuropathy Study: reassessment of tests and criteria for diagnosis and staged severity. Neurology 1992;42:1164-70.

47 Salerno DF, Werner RA, Albers JW, et al. Reliability of nerve conduction studies among active workers. Muscle Nerve 1999;22:1372-9.

48 Albers JW. Clinical neurophysiology of generalized polyneuropathy. J Clin Neurophysiol 1993;10:149-66.

49 Jamal GA, Hansen S, Pilkington A, et al. A clinical neurological, neurophysiological, and neuropsychological study of sheep farmers and dippers exposed to organophosphate pesticides. Occup Environ Med 2002; 59:434-41.

50 Misra UK, Nag D, Khan WA, et al. A study of nerve conduction velocity, late responses and neuromuscular synapse functions in organophosphate workers in India. Arch Toxicol 1988;61:496-500.

51 Stokes L, Stark A, Marshall E, et al. Neurotoxicity among pesticide applicators exposed to organophosphates. Occup Environ Med 1995;52:648-53.

52 Steenland K, Jenkins B, Ames RG, et al. Chronic neurological sequelae to organophosphate pesticide poisoning. Am J Public Health 1994;84:731-6.

53 Shy ME, Frohman EM, So YT, et al. Quantitative sensory testing: report of the Therapeutics and Technology Assessment Subcommittee of the American Academy of Neurology. Neurology 2003:60:898-904.

54 Salvi RM, Lara DR, Ghisolfi ES, et al. Neuropsychiatric evaluation in subjects chronically exposed to organophosphate pesticides. Toxicol Sci 2003;72:267-71. 